\title{
Shock tube and modeling study of 2,7-dimethyloctane pyrolysis and oxidation
}

\author{
Sijie $\mathrm{Li}^{1}$, S. Mani Sarathy ${ }^{2}$, David F. Davidson ${ }^{1}$, Ronald K. Hanson ${ }^{1}$, \\ Charles K. Westbrook ${ }^{3}$ \\ ${ }^{1}$ Department of Mechanical Engineering, Stanford University, Stanford, CA 94305, United \\ States \\ ${ }^{2}$ Clean Combustion Research Center, King Abdullah University of Science and Technology, \\ Thuwal 23955-6900, Kingdom of Saudi Arabia \\ ${ }^{3}$ Lawrence Livermore National Laboratories, Livermore, CA 94551, United States
}

\begin{abstract}
High molecular weight iso-paraffinic molecules are found in conventional petroleum, Fischer-Tropsch (FT), and other alternative hydrocarbon fuels, yet fundamental combustion studies on this class of compounds are lacking. In the present work, ignition delay time measurements in 2,7-dimethyloctane/air were carried out behind reflected shock waves using conventional and constrained reaction volume (CRV) methods. The ignition delay time measurements covered the temperature range 666-1216 K, pressure range 12-27 atm, and equivalence ratio of 0.5 and 1 . The ignition delay time temperatures span the low-, intermediateand high-temperature regimes for 2,7-dimethyloctane (2,7-DMO) oxidation. Clear evidence of negative temperature coefficient behavior was observed near $800 \mathrm{~K}$. Fuel time-history measurements were also carried out in pyrolysis experiments in mixtures of 2000 ppm 2,7$\mathrm{DMO} /$ argon at pressures near 16 and $35 \mathrm{~atm}$, and in the temperature range of 1126-1455 K. Based on the fuel removal rates, the overall 2,7-DMO decomposition rate constant can be represented with $\mathrm{k}=4.47 \times 10^{5} \exp (-23.4[\mathrm{kcal} / \mathrm{mol}] / \mathrm{RT}) \quad[1 / \mathrm{s}]$. Ethylene time-history measurements in pyrolysis experiments at 16 atm are also provided. The current shock tube dataset was simulated using a novel chemical kinetic model for 2,7-DMO. The reaction mechanism includes comprehensive low- and high-temperature reaction classes with rate constants assigned using established rules. Comparisons between the simulated and experimental data show simulations reproduce the qualitative trends across the entire range of conditions tested. However, the present kinetic modeling simulations cannot quantitatively reproduce a number of experimental data points, and these are analyzed herein.
\end{abstract}

\section{Keywords}

2,7-dimethyloctane, ignition delay time, NTC region, Fuel time-history, Ethylene time-history 
Revised Submission to Combustion and Flame, January 212015

\section{Introduction}

Branched alkanes form a major fraction of many important hydrocarbon distillate fuels including gasoline, diesel and jet kerosene. These fuels are fundamentally different from straightchain or normal alkanes. Methyl substitution (i.e., chain branching) changes the electronic pattern of the molecule, interrupts the effective straight chain length, and determines the principal point of oxidative attack on the hydrocarbon [1]. Previous studies have shown that alkanes with methyl substitutions generally have lower reactivity and lower knocking tendency [2] than normal alkanes, and a close correlation between the degree of carbon chain branching and octane rating has been observed [3,4]. Recent research has focused on symmetric dimethyl alkanes, an important sub-group of branched alkanes that offer the advantage of kinetic modeling simplicity.

Griffiths and coworkers [5-7] measured the spontaneous ignition of a range of alkanes $\left(\mathrm{C}_{4}-\mathrm{C}_{8}\right)$ using rapid compression machines and developed kinetics models describing for the lowtemperature behavior of these species. This work included studies of the branched alkanes 2,2dimethylpentane, 2,4-dimethylpentane and 3,3-dimethylpentane that helped form the basis for more complex kinetics models for the larger branched alkanes. Ji et al. [8] studied laminar flame speeds in mixtures of 3-methylheptane/air, 2,5-dimethylhexane/air and iso-octane/air. By comparing with the laminar flame speed data of 2-methylheptane/air and n-octane/air mixtures by Sarathy et al. [9,10], Ji et al. confirmed that the overall reactivity decreases as the extent of fuel branching increases [8]. Sarathy et al. studied the flame ignition, extinction and speciation profiles for 3-methylheptane and 2,5-dimethylhexane in counterflow diffusion flames [11]. Based on the experimental data, a skeletal model was developed using the directed relation graph with expert knowledge methodology [11]. Sarathy et al. further investigated 2,5-dimethylhexane combustion using jet stirred reactor speciation, shock tube ignition delay, and rapid compression machine ignition delay data and developed a comprehensive chemical kinetic model for 2,5dimethylhexane [12]. Liu et al. [13] measured the ignition temperatures of non-premixed atmospheric flames for octane and decane isomers, including 3-methylheptane (3-MHP), 2,5dimethylhexane (2,5-DMH), iso-octane, n-octane, 2,7-dimethyloctane (2,7-DMO) and n-decane. In combination with the experimental work, a high-temperature kinetic model, comprising 826 species and 4725 reactions, was developed for n-octane, 3-MHP, 2,5-DMH, 2,7-DMO and ndecane [13]. The 2,7-DMO model was based on the high-temperature oxidation model for 2,5DMH by Sarathy et al. [11]. Good agreement was shown between experimental data and simulation results [13]. Experimental and kinetic modeling studies of 3-methylheptane combustion at low and high temperatures have been reported by Wang et al. in a shock tube and rapid compression machine [14] and Karsenty et al. in a jet stirred reactor [15]. Recently, Slavinskaya et al. [16] presented shock tube ignition delay measurements of stoichiometric 2,7$\mathrm{DMO} / \mathrm{air}$ mixtures at pressure near $16-17 \mathrm{~atm}$, temperatures ranging from $650 \mathrm{~K}$ to $1500 \mathrm{~K}$. A detailed chemical kinetic model for 2,7-DMO combustion accompanied their experimental results. 
$\mathrm{Li}$ et al. measured the ignition delay times of 2,4-dimethylpentane (2,4-DMP), 2,5dimethylhexane $(2,5-\mathrm{DMH})$ and iso-octane behind reflected shock waves, in the temperature range 1310 to $1550 \mathrm{~K}$, pressures near 1.5 and $3 \mathrm{~atm}$, and equivalence ratios of 0.5 and 1 in $4 \% \mathrm{O}_{2}$ /argon [17]. By comparing the data for $\mathrm{C}_{7}$ and $\mathrm{C}_{8}$ alkane isomers with different branching ratios, $\mathrm{Li}$ et al. showed that ignition delay time increases with branching ratio for each isomers group. In addition, a comparison of the ignition delay times of 2,4-DMP and 2,5-DMH showed that ignition delay time decreases with the straight carbon chain length.

In this study, we have extended the shock tube database for symmetric branched alkanes to longer carbon chain length by investigating ignition delay times, as well as fuel and $\mathrm{C}_{2} \mathrm{H}_{4}$ species time-histories in pyrolysis for 2,7-DMO at a range of temperatures and pressures. The species time-histories obtained under high-temperature pyrolysis conditions were used to refine an existing [13] high-temperature chemical kinetic model for 2,7-DMO. The ignition delay data spans a range of temperatures, so the 2,7-DMO kinetic model was extended to include additional reaction pathways needed to simulated low- and intermediate-temperature ignition delay.

\section{Experimental method}

\subsection{Shock tube facility}

2,7-DMO ignition delay times and species time-histories were measured behind reflected shock waves using the Stanford high-pressure shock tube (HPST). This shock tube has a $5 \mathrm{~m}$ stainless steel driven section with a $5 \mathrm{~cm}$ inner diameter and a driver section that is $3 \mathrm{~m}$ long with an inner diameter of $7.5 \mathrm{~cm}$. Shock tube driver inserts were used to achieve uniform test conditions at lower temperatures where facility effects $(\mathrm{dP} / \mathrm{dt}$ and $\mathrm{dT} / \mathrm{dt})$ at long test times are most significant [18]. In the current study, test times up to $10+\mathrm{ms}$ were achieved using tailored driver gas [19]. The incident shock speed, which is critical to the accurate determination of pressure and temperature behind reflected shocks, was determined using five piezoelectric pressure transducers that were spaced at approximately $30-\mathrm{cm}$ intervals over the last $2 \mathrm{~m}$ of the shock tube. The driven section of the shock tube was heated to $110{ }^{\circ} \mathrm{C}$ to mitigate fuel condensation on the wall and the gas temperature was monitored by a thermocouple in the shock tube. Temperatures and pressures in the post-shock region were determined from the incident shock speed at the end wall using standard normal shock relations [20]. Test gas pressure was monitored using a piezoelectric pressure transducer (Kistler Model 603B1) located $1 \mathrm{~cm}$ from the end wall. Other details concerning this shock tube can be found in [21].

Prior to each experiment, oxidation and pyrolysis mixtures were prepared manometrically in a $12.8 \mathrm{~L}$, magnetically stirred stainless steel mixing tank. To avoid condensation of the fuel, the mixing tank and mixing assembly were heated to approximately $130{ }^{\circ} \mathrm{C}$. Liquid fuel was added into the mixing tank using a gas-tight syringe, and then the oxidizer and bath gas were added. The test mixtures were stirred using a magnetically driven vane assembly for at least 1 
hour before the first shock tube experiments. At 110 and $130{ }^{\circ} \mathrm{C}$ the vapor pressure of 2,7-DMO is approximately 24 and $45 \mathrm{kPa}$, respectively [22], while the partial pressure of the fuel inside the tank, mixing assembly, and the shock tube driven section never exceeded $4 \mathrm{kPa}$ during the experiment, to ensure that 2,7-DMO remains in the vapor phase throughout the experimental process. The fuel concentrations of mixtures prepared using this manometric method were confirmed by direct measurements in the shock tube using laser absorption at $3.39 \mu \mathrm{m}$.

\subsection{Laser absorption diagnostics}

\subsubsection{He-Ne absorption of fuel}

Initial fuel concentrations were monitored during both oxidation and pyrolysis experiments using the $3.39 \mu \mathrm{m}$ output of a Spectra- Physics model 124B He-Ne laser. This fuel diagnostic relies on a quantitative laser absorption measurement using the strong absorption band found in hydrocarbons near $3.39 \mu \mathrm{m}$. Common mode rejection was used to reduce laser intensity noise. Fuel mole fraction can be determined from absorption measurements using the BeerLambert law that relates the fractional transmission exponentially to the absorption cross-section, pathlength and species concentration. Further details can be found in [21]. In support of this work, the absorption cross-section of 2,7-DMO at $3.39 \mu \mathrm{m}$ and $110{ }^{\circ} \mathrm{C}$ was measured using an FTIR instrument. Details on the FTIR measurement technique can be found in [23]. Fuel decomposition time-histories during the fuel pyrolysis process were measured using the same setup, with experimental data shown in the following sections.

\subsection{2. $\mathrm{CO}_{2}$ laser absorption of $\mathrm{C}_{2} \mathrm{H}_{4}$}

Ethylene mole fraction was measured using a two-line laser absorption technique. This strategy takes advantage of the close overlap of the $\mathrm{P}(14)$ line of the $\mathrm{CO}_{2}$ gas laser at $10.532 \mu \mathrm{m}$ (called the online wavelength) with the strong ethylene absorption band near $10.6 \mu \mathrm{m}$ [24]. Similar to the C-H stretch absorption band near $3.39 \mu \mathrm{m}$, there is a broad $\mathrm{CH}_{2}$ wag absorption feature near $10.6 \mu \mathrm{m}$ that is shared in varying, albeit weaker, strengths by other higher alkenes (e.g., propene, butene, etc.). To account for the influence of these interference species, a second measurement away from the peak $\mathrm{C}_{2} \mathrm{H}_{4}$ absorption wavelength (called the offline wavelength) using the $\mathrm{CO}_{2}$ laser $\mathrm{P}(28)$ line at $10.675 \mu \mathrm{m}$ was carried out after each online measurement using the $\mathrm{P}(14)$ line. Using the different $\mathrm{C}_{2} \mathrm{H}_{4}$ absorbances in each of the online and offline measurements, and the assumption (verified by measurement) that the absorbance from other species (primarily larger alkenes) is independent of wavelength in this spectral region, the interference species effects can be subtracted and the ethylene mole fraction can be deduced algebraically [24]. The experimental setup for fuel and ethylene diagnostics can be found in Figure 1. 


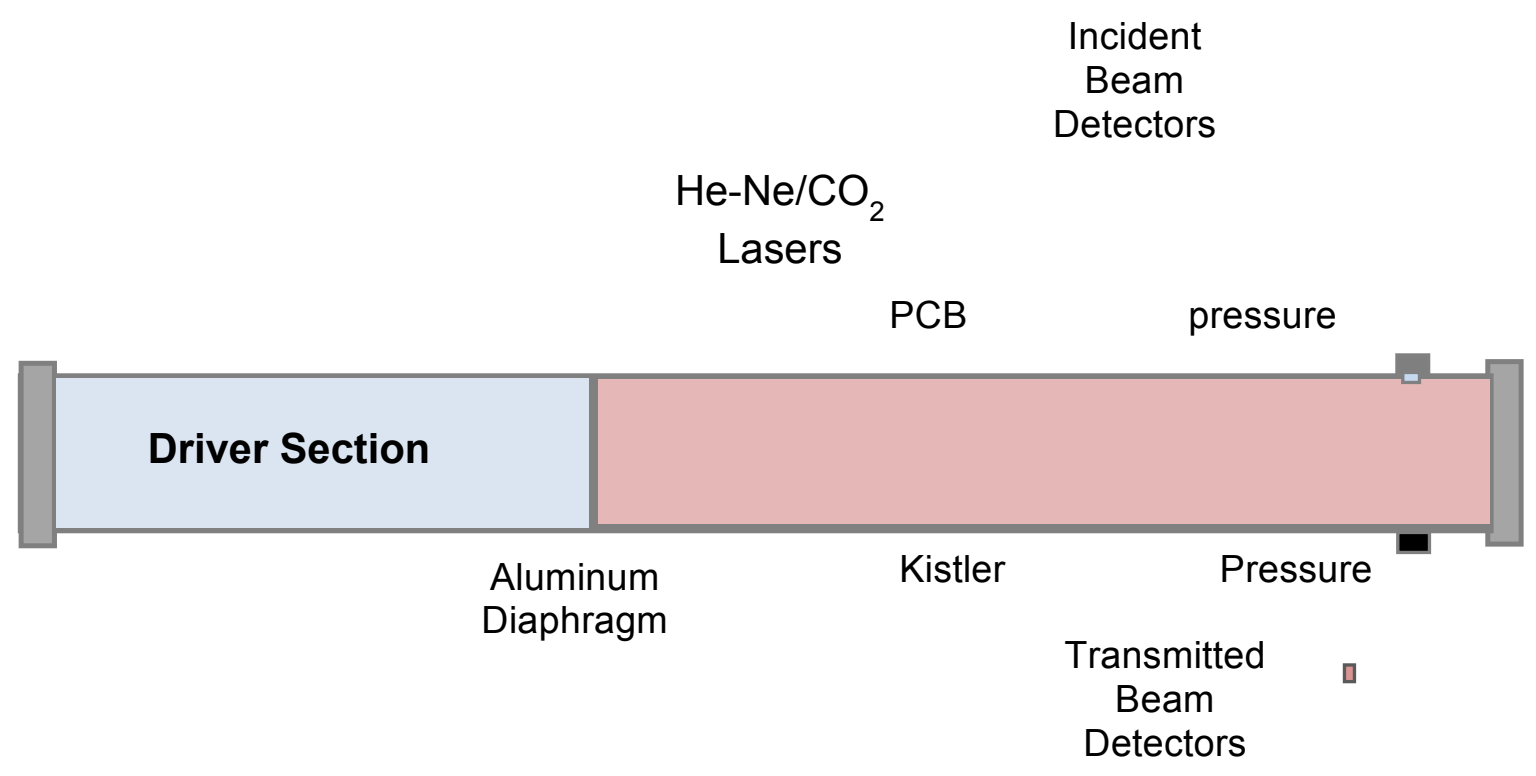

Fig 1. Schematic of the shock tube and laser absorption diagnostic.

\subsection{Constrained-reactor-volume strategy}

Both the conventional shock tube filling method and the constrained reaction volume method $[25,26]$ were used for the ignition delay time measurements. The constrained reaction volume (CRV) strategy is a new shock tube test-gas-loading method that limits the volume of reacting gases and enables reflected shock wave experiments with near-constant-pressure test conditions. Using this method, experimental data can be readily compared with constantenthalpy/constant-pressure simulations. Details about the CRV strategy can be found in $[25,26]$.

In a constrained-reaction-volume experiment using staged-filling as was done here, only a small portion of the driven section is filled with reactive mixtures. In the first filling stage, the reactive mixture is filled into the driven section of the shock tube to an initial pressure $\left(\mathrm{P}_{\mathrm{r}}\right)$. Then in the second stage, a non-reactive gas $\left(\mathrm{N}_{2}\right.$ in this study) is added to the driven section from a port close to the diaphragm and $5 \mathrm{~m}$ away from the endwall, compressing the reactive gas from the initial-stage fill $\left(\mathrm{P}_{\mathrm{r}}\right)$ to a small "slug" and to the final driven-section pressure $\mathrm{P}_{1}$. The nominal length $\left(\mathrm{L}_{1}\right)$ of the reactive "slug" before shock can be calculated using equation 1 :

$$
\mathrm{L}_{1}=(5 \mathrm{~m}) \mathrm{P}_{\mathrm{r}} / \mathrm{P}_{1}
$$

The reactive "slug" is compressed during the shock experiment, and the nominal length $\left(\mathrm{L}_{5}\right)$ of the reactive "slug" behind the reflected shock can be inferred simply according to equation 2 :

$$
\mathrm{L}_{5}=\left(\rho_{1} / \rho_{5}\right) \mathrm{L}_{1}
$$


where $\rho_{1}$ is the pre-shock static gas density after the second filling stage in the "slug"or region 1 , and $\rho_{5}$ refers to the gas densities behind the reflected shock $[25,26]$. In the current study, $\mathrm{L}_{5}$ was maintained around $5 \mathrm{~cm}$ to achieve close to a constant-pressure condition and also avoid extensive dilution of the test gas during the filling process. In Region 1 the test gas is at the preshock conditions; in Region 2 the test gas is at the conditions behind the incident shock wave; and in Region 5 the test gas is at the conditions behind the reflected shock wave.

As noted above, the $3.39 \mu \mathrm{m}$ He-Ne laser diagnostic was used to monitor the fuel concentration throughout the filling process, i.e. beginning with the time just before a shock was fired, and during the shock wave experiment. Figure 2 presents the shock-based absorbance in regions 1, 2 and 5. Even at low fuel loadings $(\phi=0.2)$ the fuel concentrations in region 1,2 and 5 were found to match well with each other, and are only slightly lower than the fuel concentration during the first filling stage. The good match of fuel concentrations in regions 1, 2, 5 gave strong confidence in the fuel uniformity in the reactive region. The drop in fuel concentration from the first filling stage is primarily caused by slight dilution during the staged-filling process. The gradient in fuel concentration in the test gas volume because of this dilution is very small as confirmed by the lack of significant slope in the measured fuel concentration between the incident and reflected shock arrivals. In order to perform ignition delay experiments at the desired fuel concentration, test gas mixtures with higher fuel concentrations were prepared in the mixing tank to account for the dilution during staged-filling, and the He-Ne diagnostic was used to confirm the final fuel concentration.

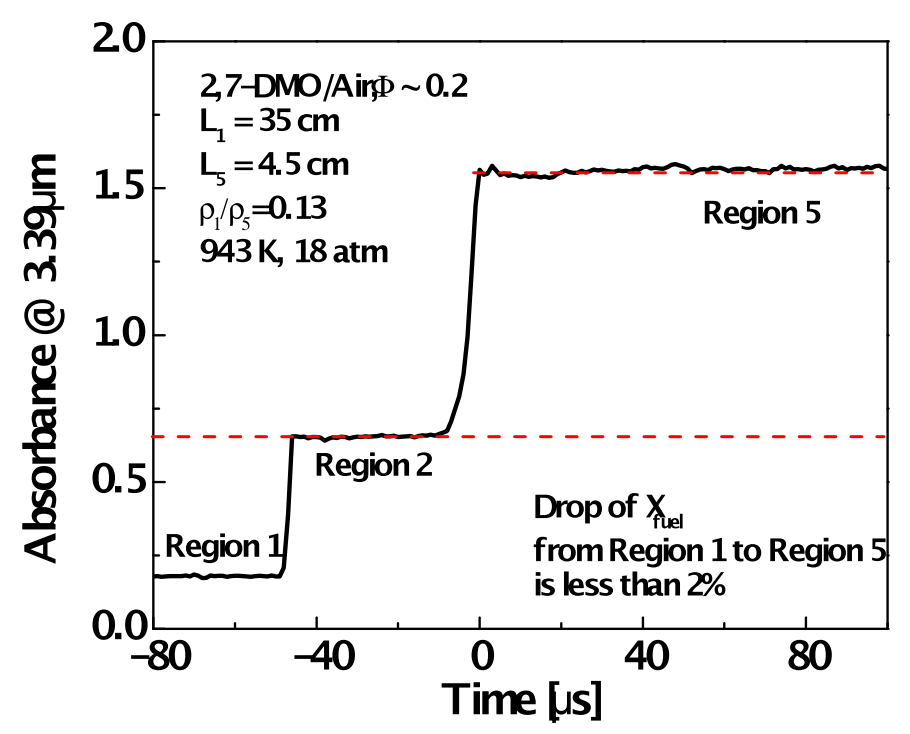

Fig 2. Representative absorbance trace at $3.39 \mu \mathrm{m}$ to confirm the fuel concentration for CRV experiment. 


\section{Chemical kinetic modeling}

The present chemical kinetic model includes high-temperature kinetic pathways for 2,7DMO [13] plus new low-temperature kinetic schemes. The reactions were added to the comprehensive 2-MHP, 3-MHP, and 2,5-DMH kinetic model presented by LLNL and KAUST $[10,12,14]$. The base $\mathrm{C}_{0}-\mathrm{C}_{5}$ mechanism used here was developed by NUI Galway and includes their recent $\mathrm{C}_{0}-\mathrm{C}_{2}$ AramcoMech 1.3 [27]. The $\mathrm{C}_{6}-\mathrm{C}_{7}$ alkane sub-mechanism is from Mehl et al. [28], and the $\mathrm{C}_{5}-\mathrm{C}_{7}$ alkenes sub-mechanism is from Mehl et al. [28,29]. A subset of hightemperature reactions for 2,6-dimethylheptane (i.e., $\mathrm{C}_{9}$ isomer) and its radicals were needed to accurately simulate the combustion of 2,7-DMO [13], so these were included in the kinetic model. The structure of 2,7-DMO is presented in Fig. 3 with carbon sites labeled according to the scheme described in [13].

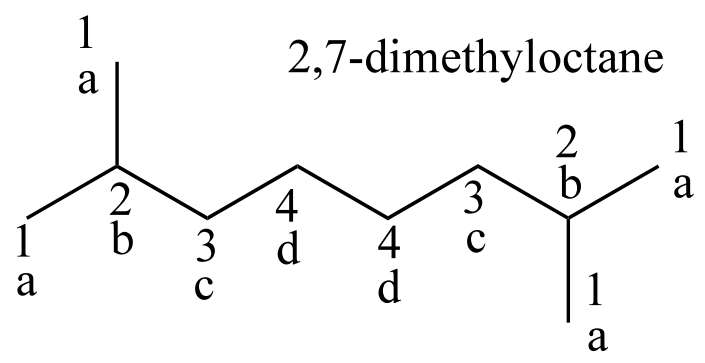

Fig. 3. Carbon skeletal structure of 2,7-DMO with carbon sites labeled

The major classes of elementary reactions considered for the oxidation of 2,7-DMO include 10 high-temperature reaction classes and 20 low-temperature reaction classes. These reaction classes and the selected reaction rate rules for branched alkanes have been described in detail previously [10]. The major classes of elementary reactions considered for the oxidation of 2,7DMO include the following:

\section{$\underline{\text { High-Temperature Reaction Classes }}$}

1. Unimolecular fuel decomposition

2. H-atom abstraction from the fuel

3. Alkyl radical decomposition

4. Alkyl radical isomerization

5. H-atom abstraction reactions from alkenes

6. Addition of radical species $\mathrm{O}$ and $\mathrm{OH}$ to alkenes

7. Reactions of alkenyl radicals with $\mathrm{HO}_{2}, \mathrm{CH}_{3} \mathrm{O}_{2}$, and $\mathrm{C}_{2} \mathrm{H}_{5} \mathrm{O}_{2}$

8. Alkenyl radical decomposition

9. Alkene decomposition

10. Retroene decomposition reactions 


\section{Low-Temperature Reaction Classes}

11. Addition of $\mathrm{O}_{2}$ to alkyl radicals $\left(\mathrm{R}+\mathrm{O}_{2}=\mathrm{ROO}\right)$

12. $\mathrm{R}+\mathrm{ROO}=\mathrm{RO}+\mathrm{RO}$

13. $\mathrm{R}+\mathrm{HO}_{2}=\mathrm{RO}+\mathrm{OH}$

14. $\mathrm{R}+\mathrm{CH}_{3} \mathrm{O}_{2}=\mathrm{RO}+\mathrm{CH}_{3} \mathrm{O}$

15. Alkyl peroxy radical isomerization $(\mathrm{ROO}=\mathrm{QOOH})$

16. Concerted eliminations $\left(\mathrm{ROO}=\right.$ alkene $\left.+\mathrm{HO}_{2}\right)$

17. $\mathrm{ROO}+\mathrm{HO}_{2}=\mathrm{ROOH}+\mathrm{OH}$

18. $\mathrm{ROO}+\mathrm{H}_{2} \mathrm{O}_{2}=\mathrm{ROOH}+\mathrm{HO}_{2}$

19. $\mathrm{ROO}+\mathrm{CH}_{3} \mathrm{O}_{2}=\mathrm{RO}+\mathrm{CH}_{3} \mathrm{O}+\mathrm{O}_{2}$

20. $\mathrm{ROO}+\mathrm{ROO}=\mathrm{RO}+\mathrm{RO}+\mathrm{O}_{2}$

21. $\mathrm{ROOH}=\mathrm{RO}+\mathrm{OH}$

22. RO decomposition

23. $\mathrm{QOOH}=$ cyclic ether $+\mathrm{OH}$ (cyclic ether formation via cyclisation of diradical)

24. $\mathrm{QOOH}=$ alkene $+\mathrm{HO}_{2}$ (radical site beta to $\mathrm{OOH}$ group)

25. $\mathrm{QOOH}=$ alkene + carbonyl $+\mathrm{OH}$ (radical site gamma to $\mathrm{OOH}$ group)

26. Addition of $\mathrm{O}_{2}$ to $\mathrm{QOOH}\left(\mathrm{QOOH}+\mathrm{O}_{2}=\mathrm{OOQOOH}\right)$

27. Isomerization of $\mathrm{OOQOOH}$ and formation of carbonylhydroperoxide and $\mathrm{OH}$

28. Decomposition of carbonylhydroperoxide to form oxygenated radical species and $\mathrm{OH}$

29. Cyclic ether reactions with $\mathrm{OH}$ and $\mathrm{HO}_{2}$

30. Decomposition of large carbonyl species and carbonyl radicals

The majority of the rate constants used in the 2,7-DMO model are identical to those used for 2,5-DMH and 2-methylalkanes, as described in [10,12]. In order to improve the simulation of 2,7-DMO pyrolysis species-time histories, the A-factors for radical recombinations of methyl plus 2-methyloctyl $\left(\mathrm{CH}_{3}+\mathrm{C}_{9} \mathrm{H}_{19}-2 \mathrm{~g}\right)$ and iso-butyl plus 2-methylhexyl $\left(\mathrm{iC}_{4} \mathrm{H}_{9}+\mathrm{eC}_{6} \mathrm{H}_{13}\right)$ to produce 2,7-DMO (i.e., reverse of 2,7-DMO unimolecular decomposition) were decreased by a factor of two to $5.0 \times 10^{12} \mathrm{~cm}^{3} \mathrm{~mol}^{-1} \mathrm{~s}^{-1}$ and $4.0 \times 10^{12} \mathrm{~cm}^{3} \mathrm{~mol}^{-1} \mathrm{~s}^{-1}$, respectively. These modifications are within the uncertainty ranges of these rate constant estimates. The rate constants for reactions in the low and negative temperature coefficient (NTC) temperature regime (e.g., Classes 11-30) were adopted from the model for 2,5-DMH [12]. Theoretical work of Wijaya et al. [30] concluded that multiple methyl substitutions in the cyclic transition state reduce the barrier height for formation of cyclic ethers because of reduced alkyl strain. In 2,5$\mathrm{DMH}$, the rate constants for cyclic ether formation were increased by a factor of 3 , which follows directly from the work of Mehl et al. on iso-octane [28]. In the present 2,7-DMO model, the same factor of 3 increase was applied, but only for those reactions producing a cyclic structure with multiple methyl substitutions on the ring. The thermochemistry values were computed using the THERM [31] software. The THERM group values are from Benson [32] and Lay et al. [33]. The entire model consists of 1571 species and 6833 reactions, and the CHEMKIN input files are available as Supplementary material to this publication and from 
websites at KAUST http://cpc.kaust.edu.sa and LLNL $\underline{\text { http://www- }}$ pls.llnl.gov/?url=science and technology-chemistry- combustion-mechanisms .

\section{Results and discussion}

\subsection{Ignition delay times}

2,7-DMO ignition delay times were measured using both the conventional shock tube filling strategy and the CRV strategy, over the temperature range 666-1216 K, and pressure range 12.2-27 atm. Driver inserts were used for all the experiments to reduce the non-ideal pressure variation caused by viscous effects, and to achieve longer test time with smaller pressure variation behind the reflected shock waves. Some sample pressures traces are shown for conventional and CRV filling, respectively, in Figures 3 and 4. Figure 3 shows an experiment using the conventional shock tube filling strategy; here pressure increases dramatically at ignition. Also included in Figure 3 is an emission signal from excited $\mathrm{OH}$ radical $\left(\mathrm{OH}^{*}\right)$. The emission signal near $306 \mathrm{~nm}$ from the $\mathrm{A}^{2} \Sigma^{+}-\mathrm{X}^{2} \Pi(0,0)$ band of $\mathrm{OH}^{*}$ was detected using a modified UV-enhanced PDA36A Si detector and Schott UG5 filter with an optical arrangement that provided a temporal resolution of better than $10 \mathrm{~s}$ [34]. The ignition delay time was determined by extrapolating, back to the baseline, the steep increase in emission signal concurrent with ignition. For the conventional shock tube filling strategy, ignition delay times can also be determined using pressure traces. The ignition delay times using the two methods matched well with each other. Previous studies have used standard constant-internal-energy and constant-volume models to simulate ignition delay times in conventional shock tube experiments [35].

Figure 4 shows two pressure traces for the CRV strategy, one for the nonreactive case and one for the reactive case. As can be seen for the nonreactive pressure trace, nearly constant pressure was achieved except for a transient bump $(<10 \%$ pressure rise) caused by shock wave interaction with the contact surface over a period $\sim 2 \mathrm{~ms}$. The test gas temperature is expected to vary only weakly (isentropically with the pressure) during this pressure excursion. This variation is not expected to have a significant effect on the ignition delay time, especially in the NTC regime where there is almost no variation of $\tau_{\text {ign }}$ with $\mathrm{T}$. To test our hypothesis that the pressure variation seen in the CRV experiments has only a minor effect on the measured ignition delay times and that constant-pressure simulations can be used, we performed ignition time calculations with different pressure profiles to test our hypothesis.

The experiment shown in Figure 4 for $762 \mathrm{~K}$, is in the middle of the NTC regime where the pressure sensitivity is expected to be strongest. This experiment should show the largest variation (of our entire dataset) in ignition delay time due to variations in pressure. The simulated ignition delay time for the constant pressure simulation is $4.82 \mathrm{~ms}$. The simulated ignition delay time using the measured pressure time-history is $3.84 \mathrm{~ms}$. This is $20 \%$ shorter than the constant-pressure simulation. (Similar calculations done at $950 \mathrm{~K}$, show only a $10 \%$ 
difference.) As this maximal variation falls within the expected uncertainty of these long-testtime ignition delay time measurements, no modification to our use of constant-pressure modeling was deemed justified.

For the reactive pressure trace, besides the contact surface bump, only a small pressure rise was observed at ignition, which is dramatically different from the conventional shock tube filling case. Emission of $\mathrm{OH}^{*}$ was used to measure ignition delay times for CRV experiments. The emission signal (red line) corresponding to the reactive pressure trace is also included in Figure 4. The steep rise in emission signal concurrent with ignition was extrapolated back to the baseline emission to determine the ignition delay time. For the CRV experiments, representative pressure traces were used as pressure input for CHEMKIN PRO [36] simulation of ignition delay times, and compared with the results using a constant pressure input. The differences in the simulated ignition delay times, between using constant pressure and measured pressure, are less than $20 \%$. This shows that the staged-filling strategy successfully constrained the reaction volume and reduced the effect of energy release on pressure at ignition. The significance of this is that the CRV strategy enables use of a constant-enthalpy/constant-pressure (or specifiedpressure) model for simulations to compare with experimental data, and allows modeling throughout the ignition and post-ignition phases of combustion. In the accompanying figures, experimental profiles acquired using the CRV strategy were simulated using a constant-pressure constraint; those acquired using the conventional shock loading strategy were modeled using a constant-volume constraint. By contrast, the traditional modeling approach, typically used on assumption of constant $\mathrm{U}, \mathrm{V}$ is limited to times up to ignition.

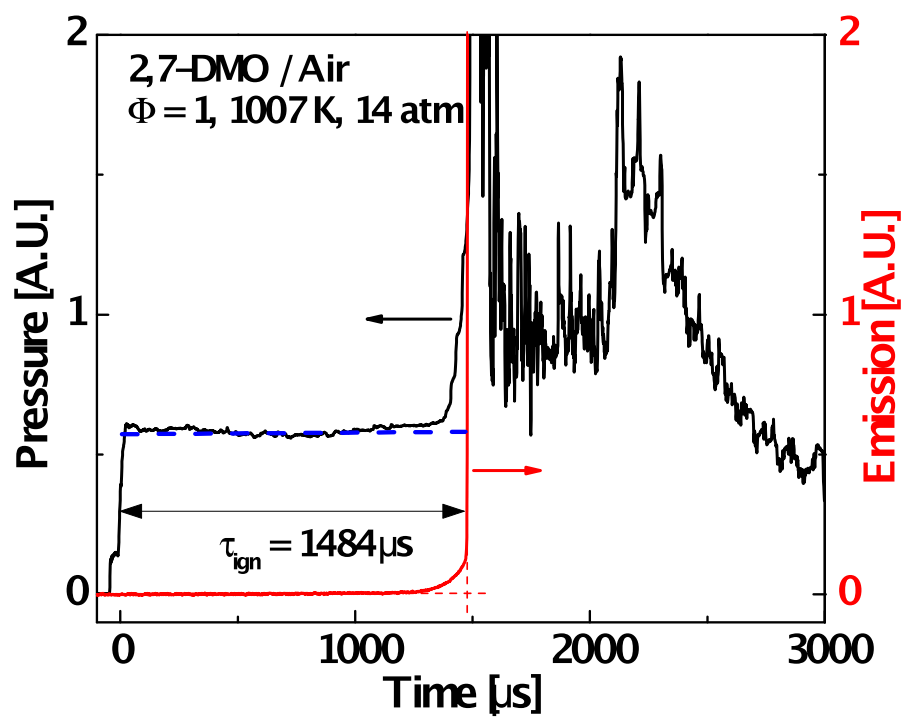

Fig 3. Representative pressure trace for the conventional shock tube filling strategy. 


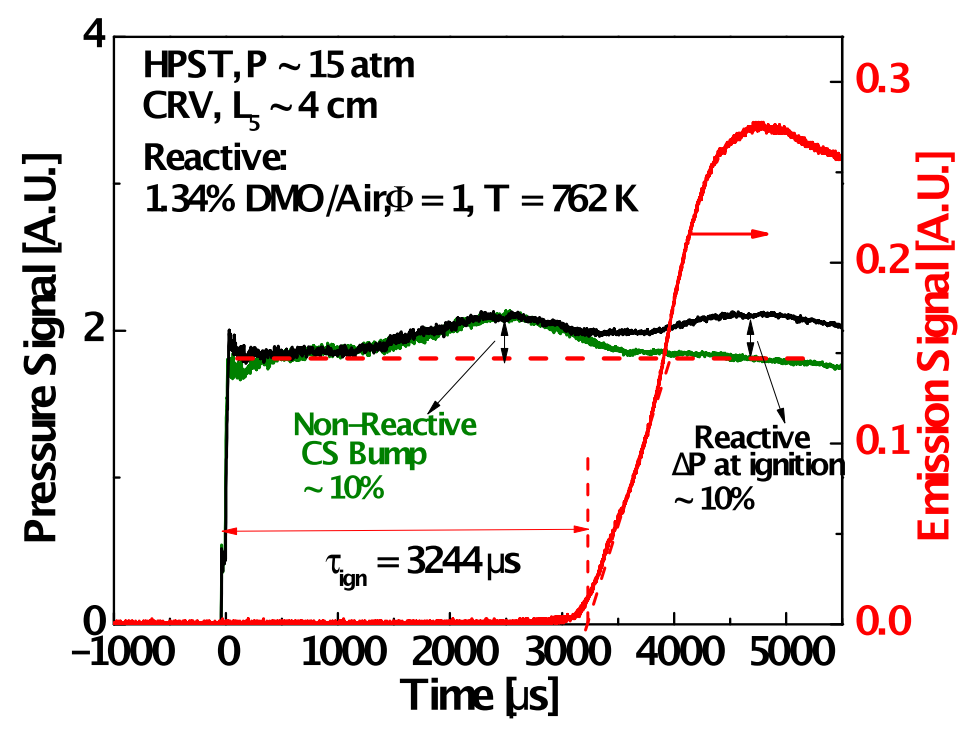

Fig 4. Representative pressure traces for constrained reaction volume (CRV) strategy.

Figure 5 shows the ignition delay times in stoichiometric mixtures of 2,7-DMO/air, using $\mathrm{CRV}$ and conventional filling. For a uniform graphic presentation of the results, a pressure scaling of all the data in a similar pressure regime is needed. In Figures 5 and 6 small corrections for variations in shock-to-shock pressure were made using a nominal $\mathrm{P}^{-1}$ scaling, (recognizing that this scaling changes with temperature particularly in the NTC regime) and that a shock tube can reproduce close, but not identical, pressures from shock to shock (see Table 1 for representative reflected pressure variations).

Over the temperature range studied, clear NTC behavior was observed around $800 \mathrm{~K}$ with both shock tube filling methods. At high temperatures (i.e., above $\sim 900-1000 \mathrm{~K}$ ), oxidation of hydrocarbon begins to be dominated by the $\mathrm{H}+\mathrm{O}_{2}$ branching reaction, and the reactivity of the mixture increases and marks the end of the NTC region. The temperature range of the NTC region depends on the pressure and the structure of the hydrocarbon. Previous studies have shown that branched alkanes have broader NTC regions, and that the low-temperature limit of the NTC region shifts to lower temperatures [37,38] than normal alkanes. For 2,7-DMO, both the CRV and the conventional filling data show that the NTC region starts around $700 \mathrm{~K}$ and ends around $900 \mathrm{~K}$, at the current pressures. At higher temperatures (with shorter ignition delay times) the ignition delay times using the two filling methods match each other well. 


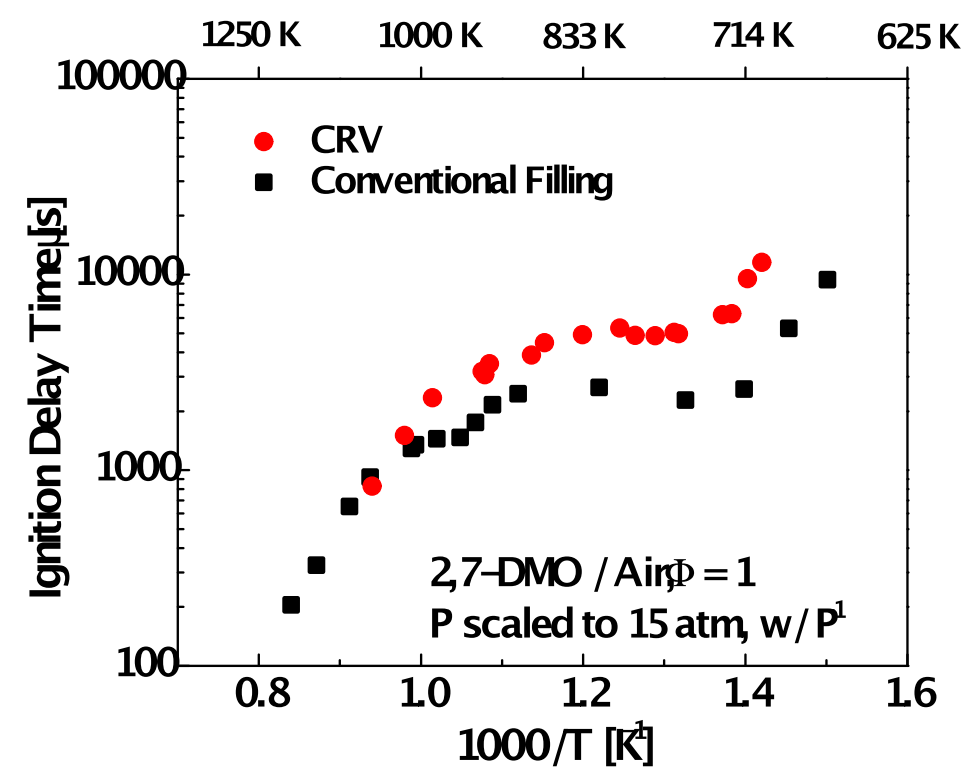

Fig 5. Ignition delay times in stoichiometric 2,7-DMO/ air mixtures, experiments using CRV and conventional filling strategy.

Ignition delay time measurements were also carried out in fuel lean mixtures with equivalence ratio of 0.5 , using the conventional filling and CRV strategy. Longer ignition delay times were observed for fuel lean mixtures than stoichiometric mixtures in the NTC region. Under the current high-pressure conditions, all the data under different equivalence ratios and using two different filling strategies converge to each other in the high-temperature regime.

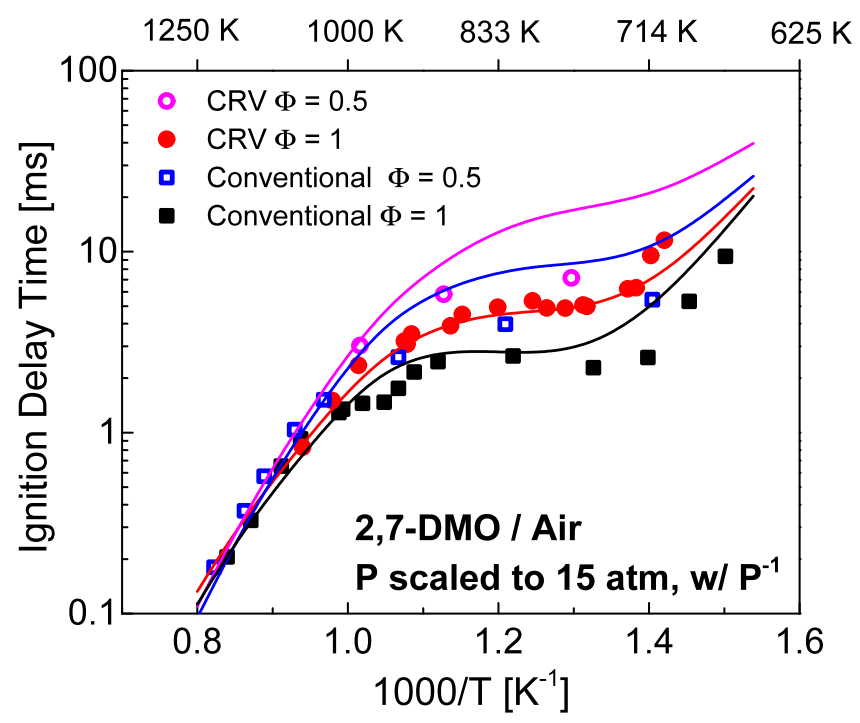

Fig 6. Ignition delay times for 2,7-DMO/ air mixtures at 15 atm and equivalence ratios of 0.5 and 1. Symbols are experiments using $\mathrm{CRV}$ and conventional filling strategy. Lines are chemical 
kinetic simulations using constant-enthalpy/constant-pressure for CRV and constant-volume for conventional filling.

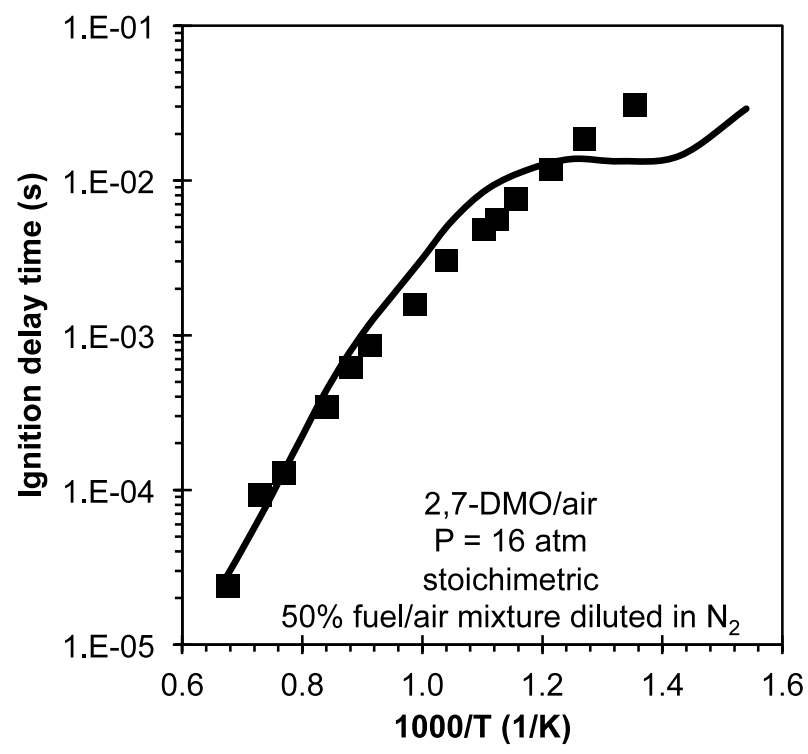

Fig. 7. Ignition delay times for 2,7-DMO/air mixtures at $16 \mathrm{~atm}$ and equivalence ratio of 1. Symbols are experimental data from Slavinskaya et al. [16] and lines are simulations using the present chemical kinetic model.

The current high-quality ignition delay time data provide valuable kinetic targets for analyzing 2,7-DMO combustion over low-, intermediate- and high-temperature regimes. All the ignition delay time data are summarized in Table 1. The ignition delay time data with the conventional shock tube filling strategy can be compared with constant internal energy and constant volume simulations (constant U, V). The data using CRV filling strategy can be modeled with constant enthalpy and constant pressure assumptions (constant $\mathrm{H}, \mathrm{P}$ ). Comparisons with specified-pressure modeling constraints demonstrate that this generally introduces errors of less than $20 \%$.

Simulations were carried out using the adiabatic closed homogenous reactor model in CHEMKIN PRO [36] to compare the chemical kinetic model with the present shock tube ignition delay time data and data available in the literature [16]. As mentioned above, constant $\mathrm{U}, \mathrm{V}$ and constant $\mathrm{H}, \mathrm{P}$ simulations were utilized to represent data obtained using the conventional filling strategy and CRV filling strategy, respectively. The lines in Figure 6 represent simulations under the various boundary conditions. At stoichiometric conditions, the simulations accurately reproduce the low-, intermediate-, and high-temperature reactivity of 2,7DMO/air mixtures, as well as the transitions between these regimes (e.g., NTC). The simulated high-temperature (i.e., above $\sim 900 \mathrm{~K}$ ) ignition delay times at both lean and rich conditions are within the uncertainty of the experimental measurements. At all temperatures, the simulated stoichiometric fuel/air ignition delay times under constant $\mathrm{U}, \mathrm{V}$ conditions are also within the 
uncertainty of the CRV measurements. However, the simulations do not well reproduce the measured ignition delay times under lean conditions and intermediate temperatures, wherein discrepancies of greater than a factor of 2 are observed. Figure 7 compares the proposed kinetic model with shock tube ignition delay data [16] for stoichiometric fuel/air mixture diluted in $\mathrm{N}_{2}$ (50\% dilution) at $16 \mathrm{~atm}$. These data are at conditions not directly comparable to those of the present study. Here too the model accurately captures the measured ignition delay times below $10 \mathrm{~ms}$. At the lowest temperatures and longest test times, the model predicts NTC behavior while the experimental data displays Arrhenius behavior across the entire range of temperatures.

Sensitivity analyses [36] can identify the reactions controlling reactivity in the NTC region. A temperature A-factor sensitivity analysis at the time of ignition was conducted at 15 atm, $833 \mathrm{~K}$, and two equivalence ratios, as shown in Figure 8. A positive normalized sensitivity coefficient indicates that increasing the reaction rate constant will increase reactivity and hence decrease ignition delay times. The decomposition of $\mathrm{H}_{2} \mathrm{O}_{2}$ to two $\mathrm{OH}$ radicals is the most sensitive reaction at these conditions, and hydrogen abstraction by $\mathrm{HO}_{2}$ from the fuel's tertiary site also exhibits a strong sensitivity, since it produces $\mathrm{H}_{2} \mathrm{O}_{2}$ while depleting the fuel $\left(\mathrm{C}_{10} \mathrm{H}_{22}-27\right)$. The recombination of two $\mathrm{HO}_{2}$ radicals to form $\mathrm{H}_{2} \mathrm{O}_{2}$ and $\mathrm{O}_{2}$ exhibits a negative sensitivity, as this competes with the hydrogen abstraction channel. Fuel-specific reactions displaying positive sensitivity include $\mathrm{H}$-atom abstractions by $\mathrm{OH}$ and subsequent low-temperature chain branching reaction classes, such as $\mathrm{O}_{2}$ addition to fuel radicals, alkyl peroxy radical isomerization $\left(\mathrm{RO}_{2}=\mathrm{QOOH}\right)$, and $\mathrm{OOQOOH}$ isomerization to form carbonylhydroperoxides and $\mathrm{OH}$. $\beta$ Scission of fuel radicals and concerted elimination from alkyl peroxy radicals display negative sensitivities, contributing to the NTC nature of 2,7-DMO. H-atom abstraction from the tertiary site also displays negative sensitivity because tertiary radicals encounter lower rates along the important low-temperature chain branching pathways [10], and higher rates in competing cyclic ether formation pathways [12].

It was previously noted that the present kinetic modeling simulation accurately reproduces measured ignition delay times in the NTC region under stoichiometric conditions, while not reproducing those under lean conditions. The sensitivity analysis identifies the challenges in rectifying this discrepancy within the present modeling framework; the sensitive reactions are similar in magnitude and direction under both lean and stoichiometric conditions. Therefore, any modification of rate constants to better reproduce the lean condition measurements would introduce undesired deviations from the stoichiometric measurements. This dilemma suggests that the present kinetic model is missing underlying chemical reaction mechanisms that contribute differently to ignition delay times at varying equivalence ratios. Another potential problem may be erroneous thermochemistry values (i.e., enthalpy of formation and entropy of formation) of important radicals along the low-temperature reaction sequence (e.g., $\mathrm{RO}_{2}, \mathrm{QOOH}$, etc.). Such inaccuracies could lead to incorrect equilibrium constants at lean and stoichiometric conditions, and thus result in discrepancies in simulated ignition delay times. In the present work, the thermochemistry values were calculated using group additivity methods. 
Improved thermochemistry calculations using quantum chemistry (e.g., [39,40,41]) and computational tools for determining sensitivity to thermochemistry (e.g., Metcalfe et al. [42]) could aid in improving the present model.

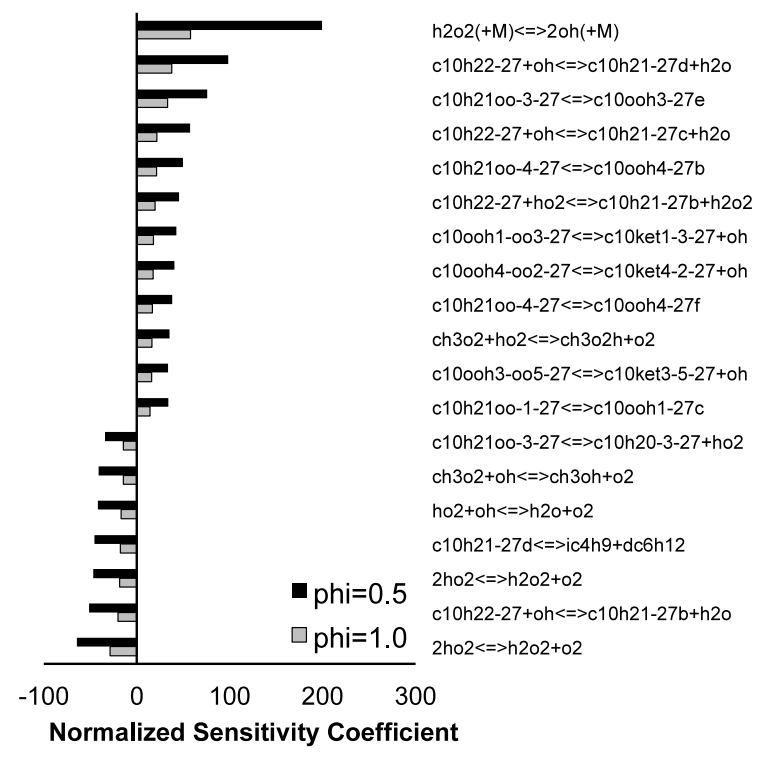

Fig. 8. Temperature A-factor normalized sensitivity coefficients at the time of ignition for 2,7-DMO in air at $15 \mathrm{~atm}$ and temperature of $833 \mathrm{~K}$.

Table 1. Ignition delay time data for 2,7-dimethyloctane

\begin{tabular}{cccc}
\hline $\begin{array}{c}\text { Equivalence } \\
\text { Ratio }\end{array}$ & T [K] & $\begin{array}{c}\text { P } \\
\text { [atm] }\end{array}$ & IDT [ s] \\
\hline \multicolumn{3}{c}{ Conventional Filling } \\
\hline $\mathbf{1}$ & 666 & 17.9 & 7903 \\
$\mathbf{1}$ & 688 & 18.7 & 4269 \\
$\mathbf{1}$ & 715 & 16.1 & 2421 \\
$\mathbf{1}$ & 754 & 16.4 & 2083 \\
$\mathbf{1}$ & 820 & 21.1 & 1884 \\
$\mathbf{1}$ & 893 & 18.5 & 2000 \\
$\mathbf{1}$ & 906 & 14.8 & 1928 \\
& 919 & 17.1 & 1895 \\
\hline
\end{tabular}


Revised Submission to Combustion and Flame, January 212015

\begin{tabular}{|c|c|c|c|}
\hline 1 & 937 & 14.5 & 1811.6 \\
\hline 1 & 954 & 13.7 & 1615 \\
\hline 1 & 981 & 16.0 & 1359 \\
\hline 1 & 1007 & 13.6 & 1483.7 \\
\hline 1 & 1012 & 13.9 & 1390.9 \\
\hline 1 & 1067 & 13.2 & 1049.7 \\
\hline 1 & 1097 & 13.1 & 746 \\
\hline 1 & 1148 & 13.0 & 375.9 \\
\hline 1 & 1191 & 12.5 & 246.8 \\
\hline 0.5 & 712 & 18.7 & 4359 \\
\hline 0.5 & 827 & 20.8 & 2859 \\
\hline 0.5 & 937 & 17.6 & 2220 \\
\hline 0.5 & 1033 & 13.5 & 1685.4 \\
\hline 0.5 & 1076 & 13.4 & 1162.1 \\
\hline 0.5 & 1125 & 13.2 & 652.8 \\
\hline 0.5 & 1159 & 12.8 & 432 \\
\hline 0.5 & 1216 & 12.2 & 221.7 \\
\hline
\end{tabular}

\section{CRV Filling}

\begin{tabular}{llll}
\hline $\mathbf{1}$ & 704 & 27.2 & 5980 \\
$\mathbf{1}$ & 713 & 27.0 & 5050 \\
$\mathbf{1}$ & 723 & 16.6 & 5160 \\
$\mathbf{1}$ & 729 & 16.2 & 5295 \\
$\mathbf{1}$ & 759 & 16.2 & 4617 \\
$\mathbf{1}$ & 762 & 20.5 & 3244 \\
$\mathbf{1}$ & 776 & 22.0 & 3318 \\
$\mathbf{1}$ & 791 & 21.7 & 3380 \\
\hline
\end{tabular}




\begin{tabular}{llll}
\hline $\mathbf{1}$ & 803 & 20.2 & 3970 \\
$\mathbf{1}$ & 834 & 18.7 & 3960 \\
$\mathbf{1}$ & 868 & 16.8 & 4005 \\
$\mathbf{1}$ & 880 & 12.7 & 4575 \\
$\mathbf{1}$ & 922 & 13.5 & 3890 \\
$\mathbf{1}$ & 927 & 13.3 & 3479 \\
$\mathbf{1}$ & 930 & 13.5 & 3558 \\
$\mathbf{1}$ & 986 & 13.1 & 2697 \\
$\mathbf{1}$ & 1021 & 11.6 & 1939 \\
$\mathbf{1}$ & 1064 & 11.0 & 1135 \\
$\mathbf{0 . 5}$ & 771 & 20.8 & 5150 \\
$\mathbf{0 . 5}$ & 887 & 18.4 & 4744 \\
$\mathbf{0 . 5}$ & 984 & 16.8 & 2700 \\
\hline & & & \\
\hline
\end{tabular}

\subsection{2,7-dimethyloctane time-history measurements}

2,7-DMO pyrolysis experiments were carried out in $2000 \mathrm{ppm}$ 2,7-DMO/argon mixtures. The fuel diagnostic at $3.39 \mu \mathrm{m}$ was used to monitor the initial fuel concentrations and to measure the fuel decomposition time-histories. Because the pyrolysis products can also absorb at 3.39 $\mu \mathrm{m}$, to correct the time-histories it was assumed that the interfering products form at the same rate as the fuel decays $[21,43]$. In other words, the pyrolysis process was modeled using the following overall reaction:

$$
2,7-\mathrm{DMO} \rightarrow \text { products }
$$

With this assumption and the ideal gas law, the fuel mole fraction can be determined from Equation 4:

$$
\mathrm{X}_{\text {fuel }}(\mathrm{t})=\left(\alpha_{\text {meas }}(\mathrm{t})-\alpha_{\text {meas }}(\infty)\right) /\left(\alpha_{\text {meas }}(0)-\alpha_{\text {meas }}(\infty)\right) \cdot \mathrm{X}_{\text {fuel }}(0)
$$

where $\alpha_{\text {meas }}(t)$ is the measured absorbance as a function of time, $\alpha_{\text {meas }}(0)$ is the measured absorbance at time zero when the reflected shock arrives at the test location, and $\alpha_{\text {meas }}(\infty)$ is the absorbance due to products only when the fuel has been fully consumed. At high temperatures ( $\mathrm{T}$ $\geq 1245 \mathrm{~K}), 2,7-\mathrm{DMO}$ was fully consumed within the test time and the measured absorbance 
reached a constant value. In those cases, the measured absorbance values toward the end of the test time were used for $\alpha_{\text {meas }}(\infty)$. At lower temperatures, the measured absorbance traces were fitted using exponential decay functions and the values of the fitted absorbance curves at long time were used for $\alpha_{\text {meas }}(\infty)$.

To validate this simplified correction method, the interference species during the 2,7DMO decomposition process were simulated using the detailed kinetic model described above. The major interference species were found to be $\mathrm{C}_{3} \mathrm{H}_{6}, \mathrm{CH}_{4}, \mathrm{C}_{2} \mathrm{H}_{4}$, iso- $\mathrm{C}_{4} \mathrm{H}_{8}$, and $\mathrm{C}_{2} \mathrm{H}_{4}$, and absorption coefficients in the literature $[44,45]$ were used to calculate the absorbance due to those interference species. The absorbance due to the interference species was subtracted from the total absorbance to infer the absorbance due to 2,7-DMO and to calculate the 2,7-DMO concentration. For the current $2000 \mathrm{ppm}$ 2,7-DMO/Ar mixtures, the temperature variations during the pyrolysis process are $\sim 5 \%$, enabling use of a constant absorption cross section (an approximation), at the initial reflected shock temperature, for the entire pyrolysis process. A similar approach was taken for the ethylene time-histories in the following section. Similarly, under the current high-temperature/short test-time conditions for our pyrolysis studies, the pressure variation behind the reflected shock waves were small owing to use of driver inserts [18]. Hence, simulations with a constant-pressure assumption were used to compare with both the 2,7-DMO and ethylene time-histories.

In Figure 9, the representative 2,7-DMO time-histories derived using the simple correction method with Equation 4, and with the detailed kinetic model method, are shown together with an uncorrected trace. We see that the simple correction method satisfactorily reduces the influences of interference species, and matches well with the method based on the detailed mechanism.

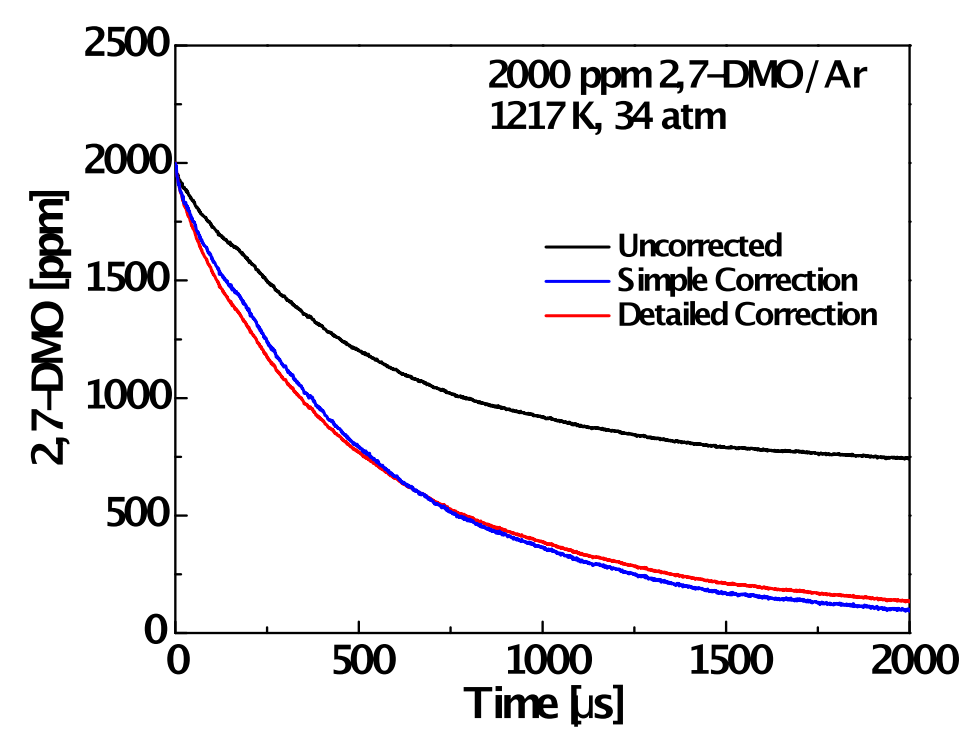


Fig 9. Sample 2,7-DMO traces with simple and detailed correction methods for interference species at $3.39 \mu \mathrm{m}$.

The 2,7-DMO time-histories under different temperatures, determined using Equation 4, are shown in two different pressure windows, with pressures of 15.7 to 16.4 atm in Figure 10 and of 33.7 to $39 \mathrm{~atm}$ in Figure 11. At the lower temperatures of these pyrolysis experiments, some intermediate species may exist long enough to contribute to a small degree to the absorbance signal at early times, but the general exponential trends that are reported provide a good estimate of the fuel removal rates. Simulations using these estimates also are in good agreement with the ethylene data presented in the next section.

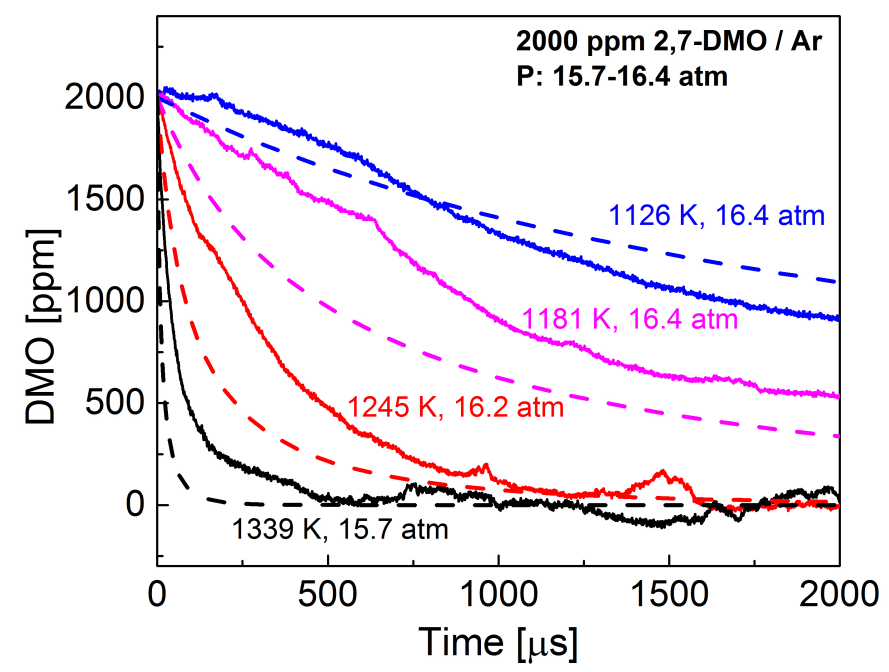

Fig 10. 2,7-DMO traces (solid lines) measured at $3.39 \mu \mathrm{m}$ under different temperatures and pressures 15.7-16.4 atm, with interference species corrected using Equation 4, and constantpressure kinetic modeling simulations (dashed lines). 


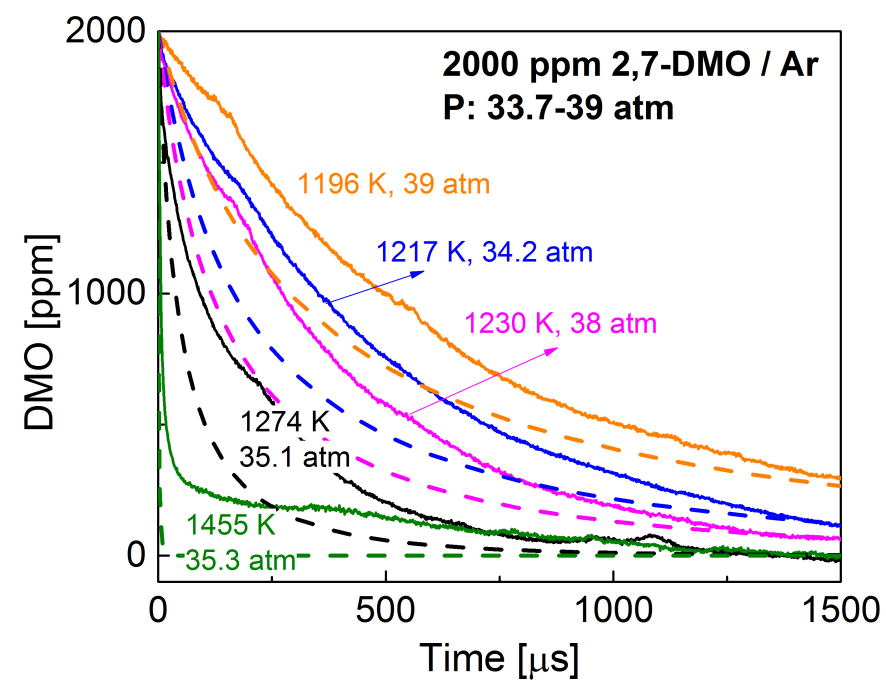

Fig 11. 2,7-DMO traces (solid lines) measured at $3.39 \mu \mathrm{m}$ under different temperatures and pressures 34-39 atm, with interference species corrected using Equation 4, and constant-pressure kinetic modeling simulations (dashed lines).

The fuel decay traces were fit using an exponential decay equation: $=\cdot-\quad+$ to get the overall 2,7-DMO removal rates at different temperatures. The Arrhenius plot for the overall 2,7-DMO removal rate constants is shown in Figure 12. It can be seen that the overall fuel decay rates in two pressures windows match with each other, which implies that the current pressures are close to the high-pressure limit of the 2,7-DMO decomposition reactions. A linear fit to the experimental data was carried out using all the experimental data, with the fitted results shown in Figure 12 as a black dash line. The following rate constant was determined for the overall 2,7-DMO removal rate:

$$
\mathrm{k}=4.47 \times 10^{5} \exp (-23.4[\mathrm{kcal} / \mathrm{mol}] / \mathrm{RT})[1 / \mathrm{s}]
$$

over temperatures of $1126-1455 \mathrm{~K}$ and pressures of 15.7 - $39 \mathrm{~atm}$. The major contributions to the uncertainty in the experimental determined reaction rate constants include: correction for interfering products $( \pm 15 \%)$, temperature $( \pm 1 \%)$, fitting error $( \pm 8 \%)$, and $2,7-\mathrm{DMO}$ absorption cross-section $( \pm 7 \%)$. The overall uncertainty for the reaction rate constant is estimated to be about $\pm 25 \%$. 


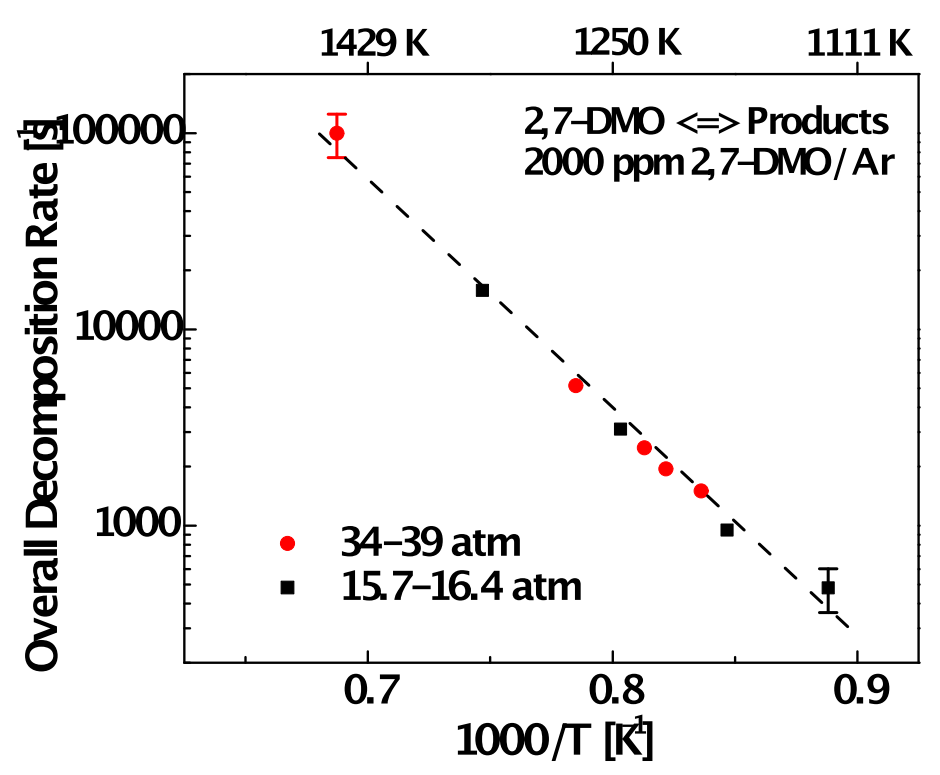

Fig 12. Overall 2,7-DMO decomposition rates inferred from the fuel measurements.

Constant-pressure kinetic modeling simulations of 2,7-DMO pyrolysis are presented in Figures 10 and 11. The simulations are in qualitative agreement with the experimental data, reproducing the shape of the fuel decay profiles as a function of time, and at reaction times greater than about 1000 microseconds, the simulations quantitatively reproduce the experimentally measured 2,7-DMO concentrations within their uncertainty limits at all temperatures and pressures. The simulated fuel concentrations at times below 200 microseconds are consistently lower than the measurements, indicating that the model is too reactive at early times. The sensitivity [36] of fuel concentration to rate constant changes is presented in Figure 13 at $16 \mathrm{~atm}, 1200 \mathrm{~K}$, and two representative test times. A negative sensitivity coefficient indicates than an increase in the reaction rate constant will decrease the concentration of 2,7DMO, and sensitivity coefficients spanning several orders of magnitude are presented. Under these high-temperature pyrolysis conditions, the fuel concentration is mainly sensitive to the rate constants of fuel unimolecular decomposition (i.e., Class 1). The $\mathrm{C}-\mathrm{C}$ bond scission reactions have sensitivity coefficients that are 3 to 4 orders of magnitude larger than other reactions, so these are clearly the rate-controlling steps. Amongst these, the decomposition involving scission between a tertiary and secondary carbon is the most important, as this is the weakest bond in the molecule. However, the large number of scission reactions that may be responsible for this variation between model and experiment precludes any unique choice of modifications to improve the fitting of the simulations. 


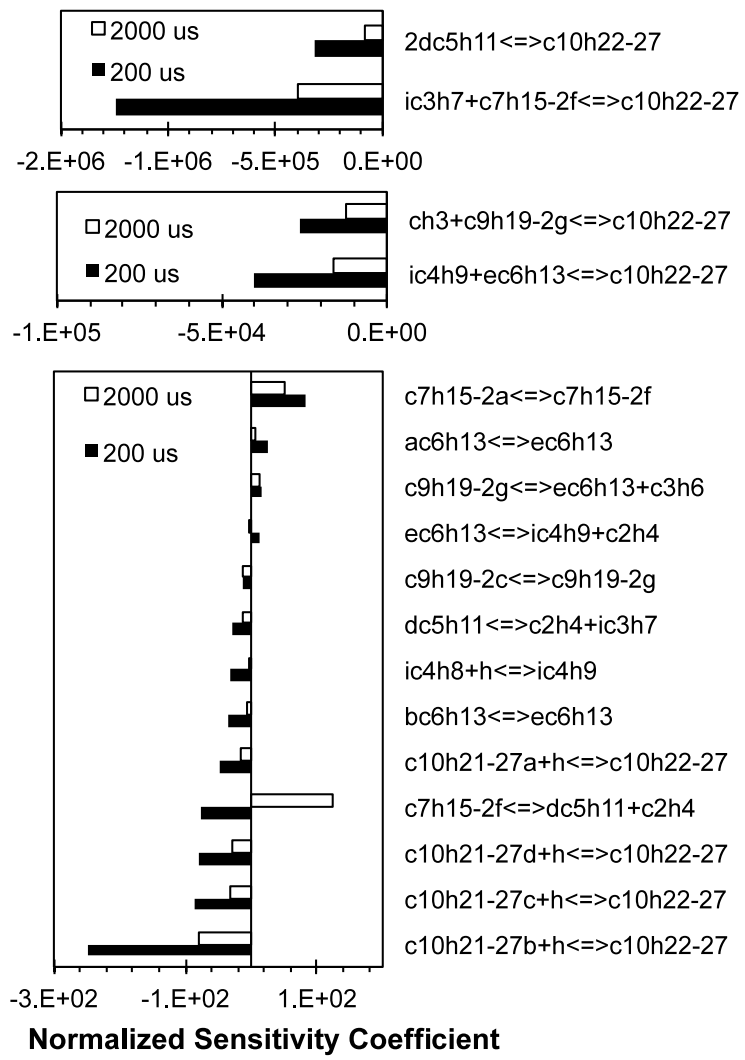

Fig. 13. 2,7-DMO A-factor normalized sensitivity coefficients at $16 \mathrm{~atm}, 1200 \mathrm{~K}$, and two reaction times.

\subsection{Ethylene time-history measurement}

Ethylene time-histories were measured making use of the $\mathrm{CO}_{2}$ laser diagnostic described in Section 2.2.2. To eliminate the interference from the weak absorption by other alkenes in this wavelength region, measurements at two wavelengths were made: one online measurement at $10.532 \mu \mathrm{m}$ and one offline measurement at $10.675 \mu \mathrm{m}$ [24]. These two measurements were carried out in separate experiments at nearly identical shock conditions (temperature difference $<$ $20{ }^{\circ} \mathrm{C}$, pressure difference $<0.3 \mathrm{~atm}$ ). Representative data for the online and offline signals are shown in Figure 14. 


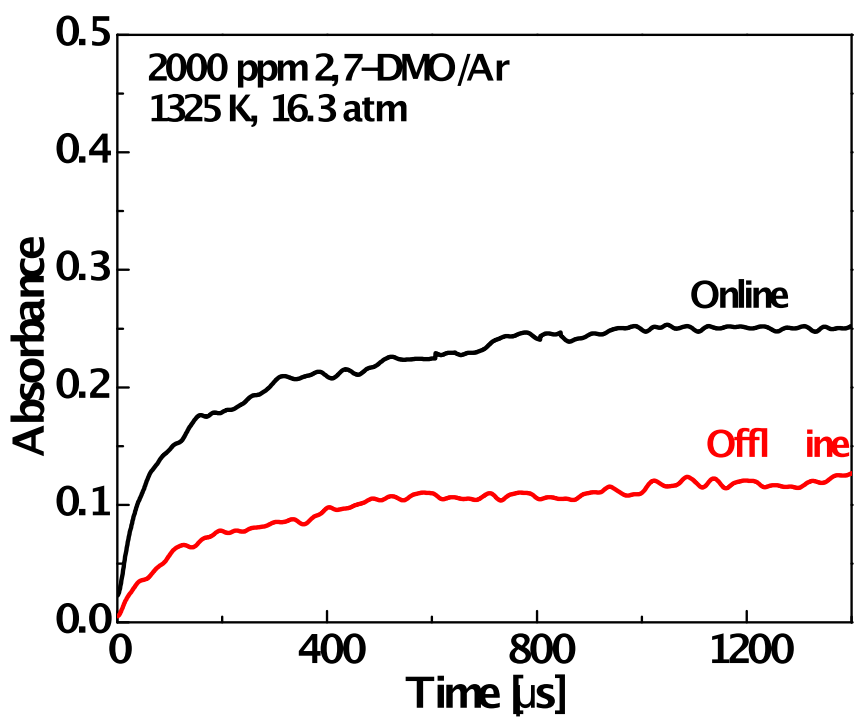

Fig 14. Representative ethylene online and offline measurement for 2,7-DMO.

As the absorption cross-sections of the interference alkenes are nearly constant in the wavelength range between 10.532 and $10.675 \mu \mathrm{m}$, and the absorption cross-sections of ethylene are known at both wavelengths, the interference (offline) absorption measurement (mathematically smoothed to a simple mathematical expression) was subtracted algebraically from the online absorption and the ethylene mole fraction was calculated [24]. The residual interference absorption in the offline measurement after subtraction of the expected ethylene absorption is consistent with the second major contributor to the offline measurement being propene. The smoothing was needed only for the interfering absorbance trace. This was done as the interfering absorbance signal has noise and but does not contain any useful information other than an average value. Using an algebraic fit (in this case a quadratic or an exponential) allowed an appropriate correction without introducing added noise to the primary signal. The online absorbance measurements were running-mean averaged because the data sample rate was of the order of $2 \mathrm{MHz}$.

The ethylene time-histories measured using this method, at different temperatures are shown in Figure 15. 


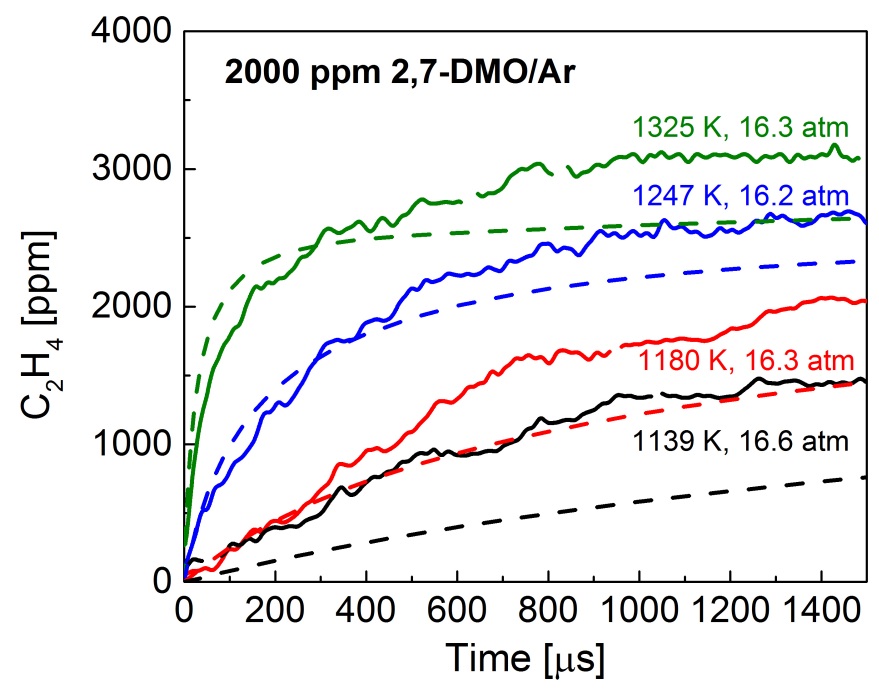

Fig 15. Measured $\mathrm{C}_{2} \mathrm{H}_{4}$ time-histories (solid lines) at different temperatures, in 2000 ppm 2,7$\mathrm{DMO} /$ Ar mixtures, and constant-pressure kinetic modeling simulations (dashed lines).

The major sources of uncertainty for the ethylene measurements result from use of the two-line differential method, the uncertainty in the ethylene absorption coefficients $( \pm 5 \%)$, the uncertainty in temperature and pressure $( \pm 1 \%)$, and the initial fuel concentration $( \pm 10 \%)$. The propagated uncertainty of ethylene yield is estimated to be $20 \%$.

The ethylene time-histories serve as an important target for kinetic model testing. Methyl substitutions are expected to affect the $\mathrm{C}-\mathrm{C}$ bond fission rates and thus influence the ethylene yield. Constant-pressure kinetic modeling simulations of ethylene production are presented in Figure 15. Qualitatively, the simulations well reproduce the early rise in $\mathrm{C}_{2} \mathrm{H}_{4}$ concentration during the first 500 microseconds and the eventual plateau. The early production of $\mathrm{C}_{2} \mathrm{H}_{4}$ correlates directly with the time history of fuel decay. Above $1200 \mathrm{~K}$, the simulated $\mathrm{C}_{2} \mathrm{H}_{4}$ concentrations are in good quantitative agreement with the experiments when their uncertainty is considered. However, the simulated $\mathrm{C}_{2} \mathrm{H}_{4}$ concentrations at lower temperatures are 1.5-2 times lower than the measurements. A sensitivity analysis for $\mathrm{C}_{2} \mathrm{H}_{4}$ concentration is presented in Figure 16 at $16 \mathrm{~atm}, 1200 \mathrm{~K}$, and two representative test times. As noted previously for 2,7-DMO, the sensitivity coefficients span several orders of magnitude and fuel unimolecular decomposition reactions are the most important. In general, increasing the fuel decomposition rate increases $\mathrm{C}_{2} \mathrm{H}_{4}$ concentrations because fuel alkyl radicals eventually decompose to $\mathrm{C}_{2} \mathrm{H}_{4}$. It is interesting to note that the fuel decomposition reactions leading to methyl $\left(\mathrm{CH}_{3}\right)$ and to iso-butyl $\left(\mathrm{iC}_{4} \mathrm{H}_{9}\right)$ display positive sensitivity at early times and negative sensitivity at later times. At early times, these reactions decompose the fuel into smaller alkyl radicals (2-methyloctyl and 2-methylhexyl) that undergo $\beta$-scission to produce $\mathrm{C}_{2} \mathrm{H}_{4}$. At later times the fuel has disappeared and $\mathrm{CH}_{3}$ radicals react with $\mathrm{C}_{2} \mathrm{H}_{4}$ to reduce its concentration via the reaction $\mathrm{C}_{2} \mathrm{H}_{4}+\mathrm{CH}_{3}=\mathrm{C}_{2} \mathrm{H}_{3}+\mathrm{CH}_{4}$. 
iso-Butyl undergoes $\beta$-scission to form $\mathrm{CH}_{3}$, thus contributing to the aforementioned scheme of reducing $\mathrm{C}_{2} \mathrm{H}_{4}$ concentration. Again, the unique reactions principally leading to these differences between model and experiment could not be identified.

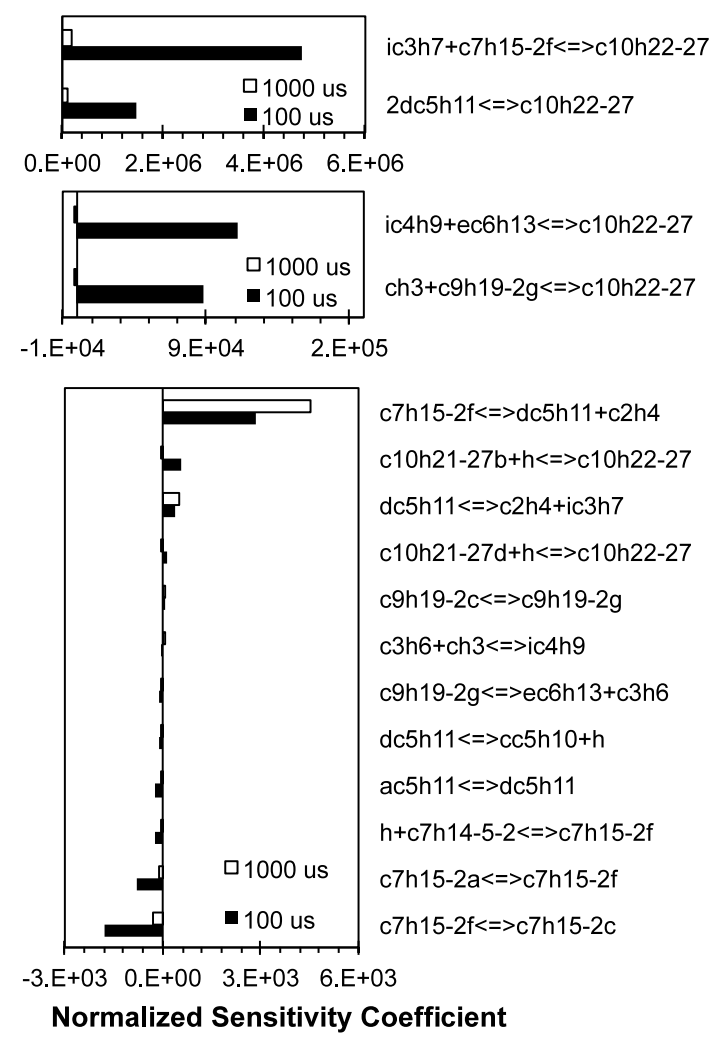

Fig. 16. $\mathrm{C}_{2} \mathrm{H}_{4} \mathrm{~A}$-factor normalized sensitivity coefficients at $16 \mathrm{~atm}, 1200 \mathrm{~K}$, and two reaction times.

\subsection{Summary}

Ignition delay times measurements and fuel and ethylene species time-histories for 2,7$\mathrm{DMO} / \mathrm{Ar}$ were carried out behind reflected shock waves using conventional and constrained reaction volume (CRV) methods with the CRV methods providing a near-constant-pressure gasdynamic test environment. Clear evidence of negative temperature coefficient behavior in the ignition delay times was observed near $800 \mathrm{~K}$. Fuel decomposition and ethylene formation measurements were measured during 2,7-DMO pyrolysis at 16 and $35 \mathrm{~atm}$, and based on the fuel removal rates, an overall 2,7-DMO decomposition rate constant was determined. The dataset was simulated using a novel chemical kinetic model for 2,7-DMO that includes comprehensive lowand high-temperature reaction classes with rate constants assigned using established rules. Comparisons between the simulated and experimental data indicated that the simulations reproduced the qualitative trends across the entire range of conditions tested, while quantitatively agreeing with the data points. An accurate representation of chain branching, chain propagation, and chain termination pathways were required for the model to reproduce 2,7-DMO ignition 
characteristics across the broad range of temperatures. Some aspects of the dataset were not quantitatively reproduced using the proposed kinetic model and potential reasons for these discrepancies were discussed. The model could not reproduce ignition delay times under lean conditions, and a traditional sensitivity analysis was unable to identify any suspect reaction rates specific to lean conditions. The model's inability to reproduce the measured equivalence ratio dependence suggests deficiencies in the reaction classes included, rate rules applied, and/or thermochemistry values. Further fundamental investigations on low-temperature oxidation of alkanes with multiple methyl substitutions is required to further refine chemical kinetic models.

\section{Acknowledgement}

This work was supported by the Air Force Office of Scientific Research through AFOSR Grant No. FA9550-11-1-0217, under the AFRL Integrated Product Team, with Dr. Chiping Li as contract monitor. The work at KAUST was funded by the Clean Combustion Research Center and by Saudi Aramco under the FUELCOM program. The LLNL work was performed under the auspices of the US Department of Energy by Lawrence Livermore National Laboratory under Contract DE-AC52-07NA27344 and was supported by the US Department of Energy, Office of Vehicle Technologies.

\section{Reference}

1. Boord C.E., in:, Prog. Pet. Technol., American Chemical Society, 1155 Sixteenth Street, N.W. Washington, D. C., 1951, pp. 353-371.

2. E. Ranzi, T. Faravelli, P. Gaffuri, E. Garavaglia, A. Goldaniga, Ind. Eng. Chem. Res. 36 (1997) 3336.

3. C. Morley, Combust. Sci. Technol. 55 (1987) 115.

4. F. Buda, R. Bounaceur, V. Warth, P.A. Glaude, R. Fournet, F. Battin-Leclerc, Combust. Flame 142 (2005) 170.

5. J.F. Griffiths, Prog. Energy Combust. Sci. 21 (1995) 25.

6. J.F. Griffiths, P.A. Halford-Maw, C. Mohamed, Combust. Flame 111 (1997) 327.

7. C.K. Westbrook, H.J. Curran, W.J. Pitz, J.F. Griffiths, C. Mohamed, S.K. Wo, Symp. Combust. 27 (1998) 371.

8. C. Ji, S.M. Sarathy, P.S. Veloo, C.K. Westbrook, F.N. Egolfopoulos, Combust. Flame 159 (2012) 1426.

9. S.M. Sarathy, C. Yeung, C.K. Westbrook, W.J. Pitz, M. Mehl, M.J. Thomson, Combust. Flame 158 (2011) 1277.

10. S.M. Sarathy, C.K. Westbrook, M. Mehl, W.J. Pitz, C. Togbe, P. Dagaut, H. Wang, M.A. Oehlschlaeger, U. Niemann, K. Seshadri, P.S. Veloo, C. Ji, F.N. Egolfopoulos, T. Lu, Combust. Flame 158 (2011) 2338. 
11. S. M. Sarathy, U. Niemann, C. Yeung, R. Gehmlich, C.K. Westbrook, M. Plomer, Z. Luo, M. Mehl, W.J. Pitz, K. Seshadri, M.J. Thomson, T. Lu, Proc. Combust. Inst. 34 (2013) 1015.

12. S.M. Sarathy, T. Javed, F. Karsenty, A. Heufer, W. Wang, S. Park, A. Elwardany, A. Farooq, C.K. Westbrook, W.J. Pitz, M.A. Oehlschlaeger, G. Dayma, H.J. Curran, P. Dagaut, Combust. Flame 161 (2014) 1444.

13. N. Liu, S. Mani Sarathy, C.K. Westbrook, F.N. Egolfopoulos, Proc. Combust. Inst. 34 (2013) 903.

14. W. Wang, Z. Li, M.A. Oehlschlaeger, D. Healy, H.J. Curran, S.M. Sarathy, M. Mehl, W.J. Pitz, C.K. Westbrook, Proceedings of the Combustion Institute 34 (2013) 335.

15. F. Karsenty, S.M. Sarathy, C. Togbé, C.K. Westbrook, G. Dayma, P. Dagaut, M. Mehl, W.J. Pitz, Energy Fuels (2012) 120803101453002.

16. N. Slavinskaya, U. Riedel, E. Saibov, J. Herzler, C. Naumann, M. Saffaripour, L. Thomas, Paper AIAA 2014-0126, 52nd Aerospace Sciences Meeting, American Institute of Aeronautics and Astronautics, 2014.

17. S. Li, A. Campos, D.F. Davidson, R.K. Hanson, Fuel 118 (2014) 398.

18. Z. Hong, G.A. Pang, S.S. Vasu, D.F. Davidson, R.K. Hanson, Shock Waves 19 (2009) 113.

19. Z. Hong, D.F. Davidson, R.K. Hanson, Shock Waves 19 (2009) 331.

20. A. Gaydon, I. Hurle, The Shock Tube in High Temperature Chemical Physics, Peinhold Publishing Co., New York, 1963.

21. S. Li, D.F. Davidson, R.K. Hanson, N.J. Labbe, P.R. Westmoreland, P. Oßwald, K. Kohse-Höinghaus, Combust. Flame 160 (2013) 1559.

22. C.L. Yaws, Yaws' Handbook of Thermodynamic and Physical Properties of Chemical Compounds, Knovel, 2003.

23. A. Klingbeil, J. Jeffries, R. Hanson, Meas. Sci. Technol. 17 (2006) 1950.

24. W. Ren, D.F. Davidson, R.K. Hanson, Int. J. Chem. Kinet. 44 (2012) 423.

25. R.K. Hanson, G.A. Pang, S. Chakraborty, W. Ren, S. Wang, D.F. Davidson, Combust. Flame 160 (2013) 1550.

26. Y. Zhu, D.F. Davidson, R.K. Hanson, Combust. Flame 161 (2014) 634.

27. W.K. Metcalfe, S.M. Burke, S.S. Ahmed, H.J. Curran, Int. J. Chem. Kin. (2013) doi:10.1002/kin.20802.

28. M. Mehl, W.J. Pitz, C.K. Westbrook, H.J. Curran, Proc. Combust. Inst. 33 (2011) 193200. 
29. M. Mehl, W. Pitz, C. Westbrook, K. Yasunaga, C. Conroy, H. Curran, Proc. Combust. Inst. 33 (2011) 201-208.

30. C. Wijaya, R. Sumathi, W. Green Jr, J. Phys. Chem. A 107 (2003) 4908.

31. E.R. Ritter, J. Bozzelli, Int. J. Chem. Kinet. 23 (1991) 767-778.

32. S.W. Benson, Thermochemical Kinetics, 2nd ed. Wiley, New york, 1976.

33. T.H. Lay, J.W. Bozzelli, A.M. Dean, E.R. Ritter, J. Phys. Chem. 99 (1995) 14514-14527.

34. W.L. Flower, Combust. Sci. Technol. 33 (1983) 17.

35. D. Horning, D. Davidson, R. Hanson, J. Propuls. Power 18 (2002) 363.

36. C. CHEMKIN PRO Release 15101, Reaction Design, Inc., San Diego, CA, CHEMKIN PRO Release 15101, Reaction Design, Inc., San Diego, CA, Reaction Design Inc, San Diego, CA, 2010.

37. K. Brezinsky, F.L. Dryer, Combust. Sci. Technol. 45 (1986) 225.

38. E.J. Silke, H.J. Curran, J.M. Simmie, Proc. Combust. Inst. 30 (2005) 2639.

39. S.M. Villano, L.K. Huynh, H.-H. Carstensen, A.M. Dean, J. Phys. Chem. A 115 (2011) 13425-42.

40. S.M. Villano, L.K. Huynh, H.-H. Carstensen, A.M. Dean, J. Phys. Chem. A 116 (2012) 5068-89.

41. C.F. Goldsmith, G.R. Magoon, J. Phys. Chem. A 116 (2012) 9033-57.

42. W.K. Metcalfe, S.M. Burke, S.S. Ahmed, H.J. Curran, International J. Chem. Kinet. 45 (2013) 638 .

43. M.E. MacDonald, W. Ren, Y. Zhu, D.F. Davidson, R.K. Hanson, Fuel 103 (2013) 1060.

44. M. MacDonald, Decomposition Kinetics of the Rocket Propellant RP-1 and Its Chemical Kinetic Surrogates, Stanford University, 2012.

45. Y. Zhu, D.F. Davidson, R.K. Hanson, Combust. Flame 161 (2014) 371. 